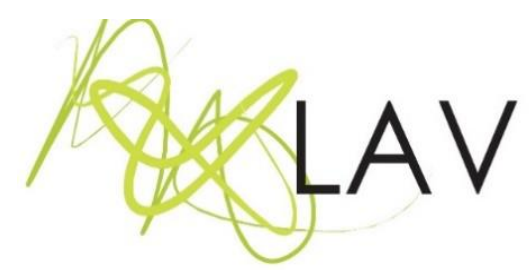

\title{
A Abordagem Triangular como possibilidade educativa para o trabalho com Dança na Educação de Jovens e Adultos (EJA)
}

\author{
El Enfoque Triangular como posibilidad educativa en la Disciplina de Arte / Danza con \\ estudiantes de Educación de Jóvenes y Adultos (EJA)
}

The Triangular Approach as an educational possibility in the Art / Dance Discipline with students of Youth and Adult Education (EJA)

Renata Celina de Morais Otelo ${ }^{i}$ Universidade Federal do Rio Grande do Norte

Marcilio de souza Vieiraii

Universidade Federal do Rio Grande do Norte

\section{Resumo}

Este artigo apresenta a escrita e as reflexões a cerca do trabalho docente vivenciado com o componente curricular Arte, especificamente com a linguagem artística da Dança, com os estudantes da Educação de Jovens e Adultos (EJA) do período noturno, da Escola Municipal Professor José de Patrocínio, localizada na zona norte de Natal, Rio Grande do Norte. O texto objetiva refletir a prática pedagógica em Arte/Dança de uma professora dessa modalidade de ensino da educação básica, assim como, apresentar possibilidades de abordar os conteúdos da Dança na EJA a partir da Abordagem Triangular de Ana Mae Barbosa (2008). A metodologia utilizada é de natureza qualitativa descritiva tendo como método a ação participante, estudada a partir de Thiollent (1984) e Silva (1986). Este estudo concluiu que os conteúdos de Arte/Dança podem contribuir na construção do corpo social dos estudantes da EJA, extrapolando práticas estreitas que enfatizam apenas as Artes Visuais, verificando que é possível inserir a Dança junto a este público educativo.

Palavras-chave: arte, abordagem triangular, corpo, dança, educação de Jovens e adultos.

\section{Resumen}

Este artículo presenta la escritura y las reflexiones a cerca del trabajo docente vivenciado con el componente curricular Arte, específicamente con el lenguaje artístico de la Danza, con los estudiantes de la Educación de Jóvenes y Adultos (EJA) del período nocturno, de la Escuela Municipal Profesor José de Patrocinio, ubicada en la zona norte de Natal, Rio Grande do Norte. El texto objetiva refleja la práctica pedagógica en Arte / Danza de una profesora de esa modalidad de enseñanza de la educación básica así como presentar posibilidades de abordar los contenidos de la Danza en la EJA, a partir del Enfoque Triangular de Ana Mae Barbosa (2008). La metodología utilizada es de naturaleza 
cualitativa descriptiva teniendo como método la acción participante, estudiada a partir de Thiollent (1984) y Silva (1986). Este estudio concluyó que los contenidos de Arte / Danza pueden contribuir en la construcción del cuerpo social de los estudiantes de la EJA, extrapolando prácticas estrechas que enfatizan apenas las Artes Visuales, verificando que es posible insertar la Danza junto a este público educativo.

Palabras clave: arte, el cuerpo, bailar, educación de jóvenes y adultos, enfoque triangular.

\begin{abstract}
This article presents writings and reflections about the teaching practice experienced with the curricular component Art, specifically with the artistic language of Dance, with the students of Youth and Adult Education (EJA) of the night period, from Escola Municipal Professor José de Patrocínio, located in the northern zone of Natal, Rio Grande do Norte. The text aims to reflect the pedagogical practice in Art / Dance of a teacher of this modality of basic education as well as to present possibilities of approaching the contents of Dance in EJA, based on the Triangular Approach of Ana Mae Barbosa (2008). The methodology used is of descriptive qualitative nature, having as a method the participant action, studied from Thiollent (1984) and Silva (1986). This study concluded that the Art/Dance content can contribute to the construction of the social body of EJA students, extrapolating narrow practices that emphasize only the Visual Arts, verifying that it is possible to insert the Dance together with this educational public.
\end{abstract}

Keywords: art, dance, body, youth and adult education, triangular approach.

Enviado em: 08/07/18 - Aprovado em: 25/11/18

\title{
Introdução
}

Partindo do pressuposto das dificuldades de se trabalhar o corpo na escola em aspectos que vão desde concepções anatômicas, filosóficas, como prática efetivas de movimentos, estando estes muitas vezes limitados as aulas de Educação Física, trazemos neste artigo a possibilidade de jovens-adultos apropriarem-se desse fazer e do saber que envolvem estas práticas voltados a disciplina de Arte a partir da linguagem artística da Dança, aos elementos que a compõe enquanto campo do saber no currículo escolar e sua colaboração no processo de ensino e aprendizagem.

Propomos nessa escrita, reflexões acerca da importância da Dança na Educação dos Jovens e Adultos (EJA) e suas contribuições enquanto conteúdo que auxilia no desenvolvimento desses estudantes, enquanto corpos dançantes.

Tal reflexão se faz necessária uma vez que o trabalho na disciplina de Arte ainda tem sido restrito ao campo das Artes Visuais (Desenho, Pintura, Fotografia, Cinema, Gravura, etc.), sobretudo, com os estudantes da EJA, por antecipar que este público não se interessaria pela linguagem artística da Dança, quando na verdade, oportunizando a esta população tais conhecimentos, poderemos trazer esclarecimentos e ampliação acerca dessa linguagem que vai além do ato de dançar e que fornece elementos que contribuem para a 
aprendizagem do sujeito em sua integralidade, incluindo a relação com o processo de alfabetização e de autoafirmação desta população.

O texto tem por objetivo compreender como se faz/aprende os conteúdos da Dança na EJA, bem como, refletir a prática pedagógica em Arte/Dança de uma professora dessa modalidade de ensino da educação básica. A metodologia usada é de natureza qualitativa, descritiva, tendo como método a ação participante. Para Thiollent (1984), a pesquisa qualitativa é descritiva; ela visa à compreensão ampla do fenômeno que está sendo estudado, considerando que todos os dados da realidade são importantes e devem ser examinados. Valoriza-se o contato direto e prolongado do pesquisador com o ambiente e a situação que está sendo estudada. Assim, os pesquisadores qualitativos tentam compreender os fenômenos que estão sendo estudados a partir da perspectiva dos participantes.

A pesquisa ação participante insere-se na pesquisa prática. Há na pesquisa participante um componente político que possibilita discutir a importância do processo de investigação tendo por perspectiva a intervenção na realidade social. Como na pesquisa-ação, a participante caracteriza-se pela interação entre pesquisadores e membros das situações investigadas; essa se desenvolve a partir da interação entre pesquisadores e membros das situações pesquisada (SILVA, 1986). Assim, na pesquisa ação participante desenvolvida com os alunos da EJA em interfaces com a Dança, buscou-se a realização concomitante da investigação e da ação; a participação conjunta de pesquisadores e de pesquisados, bem como, o objetivo de mudança ou transformação social.

\section{A Arte como disciplina: percurso histórico}

A escolarização da arte se deu a partir da vigência da Lei de Diretrizes e Bases nº 5.692/71 (BRASIL, 1971), cuja atividade recebeu a nomenclatura de "Educação Artística" e buscava contemplar o ensino das diferentes linguagens (Artes Visuais, Dança, Teatro e Música) por um único profissional que recebia uma formação polivalente na área ou que tivesse habilidades artísticas.

Vieira (2018) nos diz que a Arte era considerada apenas uma "atividade educativa" e não uma disciplina no currículo escolar, embora tenha sido incluída na Lei no. 5.692 com o título de Educação Artística. Foi um avanço considerável, tanto pelo aspecto de sustentação legal para esta prática, quanto por ter sido considerada importante na formação dos indivíduos. Porém, essa alteração criou questões novas a serem enfrentadas, principalmente para os professores de cada uma das linguagens artísticas.

Revista Digital do LAV - Santa Maria - vol. 11, n. 3, p. 122 - 137 - set./dez. 2018 ISSN 1983 - 7348 http://dx.doi.org/10.5902/1983734832833530 
Após a lei citada, iniciaram-se vários cursos de licenciatura em Artes pelo Brasil, com o intuito de sanar as adversidades que vinham ocorrendo na área, em especial ao modelo tecnicista de educação e as medidas governamentais que visavam à adequação do sistema educacional às transformações de ordem econômica, política, social e cultural, que refletiam no mundo contemporâneo na época. Havia um grande descompasso entre a teoria e a prática e devido à grande dificuldade dos professores de Educação Artística em ministrar suas aulas, surgiram muitos movimentos e organizações com o objetivo de discutir a necessidade de implantar teorias que fundamentassem suas práticas, como por exemplo, a Associação de Arte-Educadores do Estado de São Paulo (AESP), fundada em 1982 e, em 1987, a Federação Nacional dos Arte-Educadores do Brasil (FAEB), que tiveram participação significativa em congressos e seminários estaduais, nacionais e internacionais, abordando o ensino da Arte nas escolas (VIEIRA, 2018).

A criação dos cursos de licenciatura em Artes, eram em geral, com ênfase nas Artes Visuais, a fim de habilitar os profissionais em exercício e atrair docentes na área que se encontrava em expansão e, de acordo com Vieira (2018), os professores de Desenho, Música, Trabalhos Manuais, Canto Coral e Artes Aplicadas, que utilizavam para as aulas os conhecimentos específicos de suas linguagens, passaram a ver esses saberes transformados em "atividades artísticas", o que fica claro na análise do Parecer no 540/77 do Conselho Federal de Educação (BRASIL, 1977): "[...] não é uma matéria, mas uma área bastante generosa e sem contornos fixos, flutuando ao sabor das tendências e dos interesses".

Segundo Fusari e Ferraz (2010), os professores das escolas públicas encontraram dificuldades em apreender métodos de ensino nas salas de aula, resultando numa prática pouco ou nada fundamentada, necessitando de aprofundamentos teórico-metodológicos. Neste sentido, as autoras afirmam que:

Dentre os problemas apresentados no ensino artístico, após a Lei $5692 / 71$, encontram-se aqueles referentes aos conhecimentos básicos de arte e métodos para apreendê-los durante as aulas, sobretudo nas escolas públicas. O que se tem constatado é uma prática diluída, $[\ldots]$, na qual métodos e conteúdos de tendência tradicional e novista se misturam, sem grandes preocupações, com o que seria melhor para o ensino de Arte (FUSARI; FERRAZ, 2010, p. 43).

Em 1973, são aprovados o Parecer CFE n 1.284/73 e a Resolução CFE no 23/73, termos normativos acerca do curso de licenciatura em Educação Artística, que estabeleceram a licenciatura de $1^{\circ}$ grau, que capacita para o exercício profissional neste nível de ensino, também chamada de licenciatura curta em função de sua duração que proporciona uma 
habilitação geral em Educação Artística e a licenciatura plena que combina essa habilitação geral a habilitações específicas, "[...] relacionadas com as grandes divisões da Arte - Artes Plásticas, Artes Cênicas, Música e Desenho [...]" nos termos do Parecer CFE no 1.284/73 (BRASIL, 1973).

Estas linguagens artísticas, como pontua Vieira (2018), passaram a ser vistas como integrantes do campo da Educação Artística, inclusive porque vários anos decorreram até que, em 1977, o CFE se pronunciasse sobre a sua prática escolar, através do Parecer CFE no 540/77. No entanto, a "habilitação geral em Educação Artística" - à qual se reduz a licenciatura curta e que integra a licenciatura plena, constituindo o currículo mínimo da parte comum do curso indicado pela Resolução CFE n 23/73 (BRASIL, 1982) - dirige-se a uma abordagem integrada das diversas linguagens artísticas, ou seja, um tratamento polivalente. Prevista nos termos normativos tanto para a formação do professor quanto para $01^{\circ}$ e $2^{\circ}$ graus, a polivalência marcou a implantação da Educação Artística, contribuindo para a diluição dos conteúdos específicos de cada linguagem.

Vemos nas décadas seguintes à lei, que o ensino de Arte se voltava mais para as Artes Visuais, ignorando quase por completo as demais linguagens artísticas, sendo pontual as atividades com a Dança, o Teatro e a Música em festividades sazonais do calendário letivo, o que empobrecia a abordagem dos conteúdos relativos a uma área tão abrangente e múltipla (MARQUES, 2011).

Apenas no final da década de 1990, as associações, entidades e pesquisas na área de Arte passaram a preocupar-se e incluir as demais linguagens artísticas como ponto de discussão, conhecimento e documentos oficiais, a exemplo dos Parâmetros Curriculares Nacionais (BRASIL, 1997).

Desde sua composição curricular, a disciplina de Arte trava uma batalha epistemológica a fim de dissociá-la do esponaneísmo e expressividade apenas (MARQUES, 2011). Para isso, a Lei de Diretrizes e Bases n. 9394/96 apresentou avanços no que se refere ao lugar da Arte no currículo escolar enquanto conhecimento e obrigatoriedade na educação básica, seguida de discussões atuais que apresentam sua relevância ao propiciar a troca entre culturas, favorecimento e reconhecimento de semelhanças e diferenças entre elas, promovendo um diálogo intercultural, pluriétnico e plurilíngue, importantes para o exercício da cidadania (BRASIL, 2018).

A Lei n. 9.394/96, em seu Art. 26, parágrafo 2, estabeleceu que "[...] o ensino da Arte, especialmente em suas expressões regionais, constituirá componente obrigatório nos 
diversos níveis da educação básica, de forma a promover o desenvolvimento cultural dos alunos"; ela garante um espaço para as Artes na escola, como já era estabelecido na Lei anterior, com a inclusão da Educação Artística (VIEIRA, 2018).

Assim, o ensino de Artes/Dança, de acordo com a Lei, é garantido na Educação Infantil como preconiza seus referenciais, no Ensino Fundamental e no Ensino Médio tal como exposto nos Parâmetros Curriculares Nacionais e Diretrizes Curriculares Nacionais e, também, se constituiu no Ensino Superior e na Educação Profissional, mesmo antecedendo a Lei n. 9.394/96 (VIEIRA, 2008).

Percebemos quão recente a Arte se configura enquanto área curricular e como área de pesquisas acadêmicas, especialmente se falarmos da Dança como produção muito reduzida na área da educação, ainda mais se observamos esse recorte nos estudos relativos a Dança para os estudantes da EJA.

Desse modo, iniciamos juntos aos estudantes uma investigação refletindo acerca da produção artística voltada para aquilo que ocorre no corpo e pelo corpo, discutindo e significando relações entre corporeidade, produção artística e estética como conhecimento. As aulas passaram a ser planejadas pensando em articular aspectos sensíveis e epistemológicos a partir do movimento dançado, contextualizado e apreciado, subsidiada pela Abordagem Triangular de Ana Mae Barbosa (2008), cuja base se constitui no contextualizar- fazer- apreciar enquanto práticas possíveis de ensino na área.

A Abordagem Triangular de Barbosa (2008), se configura em ações e não em conteúdo; ela corresponde aos modos como se aprende e não é um modelo para o que se aprende. Para a autora, apreciar, contextualizar e fazer, são processos que podem tomar diferentes caminhos e subjaz a metáfora do triangulo na organização da estrutura pedagógica, contribuindo para estimular a materialidade da produção em grupo, a imaginação criativa e o entendimento dos princípios articuladores da obra de arte, respeitando a especificidade de cada linguagem e de cada criador.

O apreciar, contextualizar e fazer abordados por Barbosa (2008) se aplicam em qualquer instância do ensino, qualquer professor, de qualquer disciplina pode utilizar a Abordagem Triangular para desenvolver a sua metodologia e o cinema não poderia ficar de fora desse contexto, já que o filme, de certa forma, é utilizado por diferentes professores, com as intenções mais diversas.

Inicialmente, a Abordagem Triangular foi elaborada para o desenvolvimento das Artes Visuais em que a tríade se dá como um conjunto de ações complementares e 
interconectadas em que no fazer temos a dimensão de produzir obras artísticas e realizar leituras sobre elas; na apreciação temos o exercício de ler e compreender poeticamente os códigos e a estes elaborar sentidos e na contextualização se propõe estabelecer conexões com os fatores históricos, sociais, culturais de modo que tais aspectos estejam articulados e caminhem para o aprofundamento em Arte (MACHADO, 2010).

Assim, amparados pela Abordagem Triangular, o planejamento, desenvolvimento e avaliação das aulas se constituíram considerando os saberes acerca da dança e do corpo que os estudantes já traziam em sua vivência, buscando encadear aprofundamentos e acrescer novas referências a respeito da dança e seus gêneros, história e vivências sendo trabalhadas e ancoradas pela Abordagem Triangular para o ensino da Arte, formulada por Ana Mae Barbosa (2008).

Tal proposta, embora concebida a priori, para o trabalho educativo nas Artes Visuais, é aceita por grande parte dos educadores de Arte das diferentes linguagens como uma proposta possível nos espaços escolares e que contempla satisfatoriamente a abordagem dos conteúdos das demais linguagens artísticas (Teatro, Dança e Música). Foi essa tríade que alicerçou nossa prática junto aos estudantes da EJA.

\section{Os sujeitos da EJA. Quem são?}

A Educação de Jovens e Adultos (EJA) aparece como um dever de oferta do Estado, resguardado aos sujeitos que não tiveram a oportunidade de cursar em período comum escolas regulares de ensino, conforme sinaliza o Art. 37 da Lei de Diretrizes e Bases no 9394/96, ao nos assegurar que "A educação de jovens e adultos será destinada àqueles que não tiveram acesso ou continuidade de estudos no ensino fundamental e médio na idade própria".

De maneira geral, poderíamos dizer que o aluno que se insere na EJA tem uma história marcada, dotada de significados socioculturais trazidos dos seus contextos, muitas vezes, sofridos e negados por diversas razões, sejam estas econômicas, sociais, políticas e/ou familiares. Arroyo (2005, p. 30) nos ajuda na reflexão de que

Os jovens-adultos populares não são acidentados ocasionais que, ou gratuitamente, abandonaram a escola. Esses jovens e adultos repetem histórias longas de negação de direitos. Histórias coletivas. As mesmas de seus pais, avós, de sua raça, gênero, etnia e classe social.

O acervo de marcas desfavoráveis na vida desses indivíduos interferiu diretamente no processo de ensino-aprendizagem no que se refere à descontinuidade da trajetória escolar, 
sendo necessário que este percurso seja refeito com o retorno do aluno na modalidade de ensino EJA a fim de possibilitar uma reconstrução de sua vida escolar e, consequentemente, dar continuidade a sua vida pessoal e profissional.

Para isto, a escola precisa rever sua visão a respeito desse público, lançando um olhar positivo, de jovens-adultos de diretos e deveres e que, para além de "recuperar" os conteúdos, estão na escola para visualizar novos futuros, perspectivas, e como jovensadultos do seu tempo, vivenciarem processos educativos que correspondem aos desejos e demandas atuais de suas vidas.

Reforçando nossas reflexões, Malta (2005) nos aponta que as questões que envolvem o processo de aprender na Educação de Jovens e Adultos só serão compreendidas se observarmos a história dos sujeitos sócio históricos que trazem consigo os saberes aprendidos na vida e os ressignificam na prática pedagógica, margeando a trajetória que Ihe foi permitida trilhar em meio as dificuldades que encontrou em sua trajetória.

A autora acima nos adverte sobre a importância da escola como instituição que deve promover o aprofundamento dos saberes, se colocando nesse cenário no intuito de sistematizar e ampliar as possibilidades das aprendizagens trazidas por esses sujeitos a partir das suas vivências, considerando o conhecimento que é trazido pelos estudantes e partir deles, pois o "[...] processo de aprender e ensinar são, antes de tudo, processos de produção do saber, de produção do conhecimento, e não de transferência de conhecimento" (FREIRE, 2014, p. 167).

Com o retorno à escola, este aluno terá meios de aprender e alargar seu conhecimento social, humano, científico, artístico, ético e estético.

Sobre as aprendizagens que podem ser aprofundadas na escola, Malta (2005) ressalta que a aprendizagem dos conteúdos nas classes popular, constitui-se no passaporte para um melhor viver; e que assim, desejos são despertados, sonhos são mobilizados e a busca pela escola - em um período da vida considerado essencialmente para o trabalho - ganha um sentido para os educandos adultos.

Ao encontro desses desejos e sonhos, percebemos na Arte, singular capacidade em colaborar com a possibilidade de sonhar e estes sonhos serem alimentados e, ainda, ampliados ao olhar desse jovem-adulto que permitiu a reformulação de seu trajeto escolar.

A Arte tem a capacidade de tornar a trazer prazer e bem-estar em suas diferentes linguagens: Artes visuais, Dança, Teatro e Música. Os professores de Arte, junto aos 
demais professores, têm a possibilidade de contribuir para a preparação de indivíduos que percebem melhor o mundo em que vivem, para que saibam compreendê-lo e nele possam atuar de modo mais significativo e emancipado (FERRAZ; FUSARI, 2010).

Temos o discurso de que a Arte trás elementos positivos na constituição do indivíduo, mas os métodos para se construir um trabalho consistente ainda são limitados, especialmente se falarmos da Dança, já que ainda mais jovem que os estudos das Artes Visuais, por exemplo, são os estudos desta área como prática pedagógica significativa na educação.

Para desenvolver o trabalho com a Dança, investigamos, junto aos estudantes, quais danças eles já traziam em seu repertório e abordamos essas referências a partir do levantamento que conseguimos fazer, estabelecendo um paralelo com a referência das 'palavras geradoras' que Paulo Freire utilizava para o trabalho com alfabetização. Assim, escolhemos algumas danças/gêneros mais frequentes nas falas para a partir delas, desenvolver o conhecimento em Dança na perspectiva da Abordagem Triangular.

Nessa projeção de construção do conhecimento, foi fundamental pensar junto aos estudantes na perspectiva do corpo social a partir da educação sensível a fim de que eles pudessem pensar novos significados acerca do próprio corpo, de que é o corpo que nos certifica a existência de modo concreto e de que é esse corpo que trabalha, que estuda, que age, que pensa, que tece suas relações com o mundo que dança.

Desse modo, a Dança, para Porpino (2006, p. 117),

[...] aparece como possibilidade desveladora da linguagem corporal, que comumente passa despercebida aos nossos olhos na rotina de nosso cotidiano. Tal gestualidade não acontece apenas no dançar, mas a cada minuto, uma vez que somos o nosso corpo; porém, no dançar, há espaço para que a poesia do movimento seja possível, atinja-nos e nos incite à criação de novos movimentos poéticos.

A poesia perdida ou pouco observada, assim como os desejos e sonhos esquecidos, reaparece numa cultura dançante, ampliando não apenas a experiência artística do alunodançarino, mas contemplando toda a comunidade escolar, uma vez que na contextualizarfazer-apreciar dos elementos corporais e seus códigos dançantes, estão também eles, sendo inseridos numa experiência estética e artística a partir do corpo do outro e da produção dos colegas.

Foi possível perceber durante os anos da nossa prática (2011-2015), o distanciamento/dificuldade de trabalhar com o corpo nos espaços escolares, fato percebido 
pela pesquisadora em seu cotidiano escolar com alunos da EJA em escolas públicas enquanto docente de Arte - Dança, no Município de Natal, capital do estado do Rio Grande do Norte. A presença da dança e o trabalho com o corpo é pouco explorada, se desvelando em momentos pontuais dentro da escola como em datas sazonais das festividades do calendário letivo, por exemplo. Mas vale ressaltar que a educação precisa considerar a vivencia experenciada pelo sujeito que é corpo e aprende a partir dos sentidos e das experiências, gerando conhecimento.

Assim, a disciplina de Arte na EJA deve contribuir diretamente com a garantia de que os alunos conheçam e vivenciem aspectos técnicos, inventivos, representacionais e expressivos em dança, entendendo que é possível atingir uma vivência mais ampla e aprofundada das linguagens artísticas, neste caso, da dança, a partir do sensível e dos elementos da cultura dançante (FERRAZ; FUSARI, 2010).

\section{A dança como conhecimento}

Durante o período de 2011 a 2015, a professora e pesquisadora atuou na Escola Municipal Professor José do Patrocínio, localizada na zona norte do Município de Natal, Rio Grande do Norte, com turmas dos níveis II, III e IV. Nesse período, as aulas de Arte passaram a compor momentos com as três bases da Proposta Triangular: contextualizar-fazerapreciar. Partindo do repertório e vivências dos estudantes em sua comunidade, na zona norte da cidade de Natal, capital do Rio Grande do Norte, passamos a planejar aulas compreendendo momentos que propiciassem a ampliação do conhecimento em Dança.

Para a contextualização, utilizamos em vários momentos a investigação de aspectos históricos com levantamento de informações a respeito de gêneros da dança, dos grupos, Mestres da cultura popular realizando registros escritos, imagéticos com recorte e colagem, visualização de vídeos com os temas relacionados e atividades em sala abordando desde as concepções de corpo as danças propriamente ditas.

Cumpre frisar que a contextualização também deve abordar o diálogo entre as obras em estudo e a realidade social, pois a Arte não está dissociada nas questões vigentes, pelo contrário, é parte desveladora do que vivemos em nossos dias. A figura 1 apresenta um desses momentos em que o contextualizar se fez presente para que esses alunos da EJA pudessem compreender os conteúdos da Dança ministrados. 


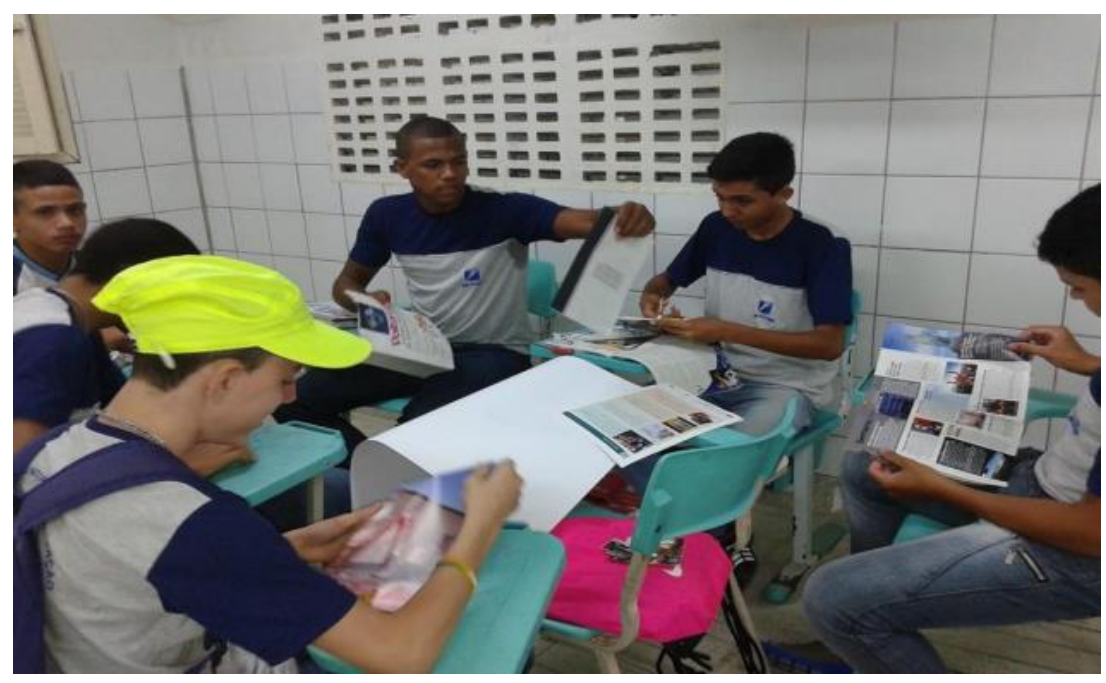

Figura 01. Estudantes da EJA em momento de atividade. Fonte: Acervo da pesquisadora (2014)

Em alguns momentos também foi possível realizar pesquisas na internet, utilizando a sala multimídia da Unidade de Ensino, aliando os aspectos tecnológicos como recurso para o estudo dos conteúdos da Dança.

No que se refere ao apreciar, trabalhamos na busca de diversificar os modos dessa apreciação junto aos estudantes, permitindo o acesso a Arte por formatos e percepções potencializando a ampliação de contextos históricos, possibilitando a diversidade de leituras e fazeres da arte/dança junto aos alunos.

Ao tratar desse vértice da proposta, vemos a necessidade da responsabilidade ética do encontro, conforme nos aconselha Isabel Marques (2010), uma vez que na Dança, em que os trabalhos apreciados não são coisas ou objetos, mas corpos-pessoas, faz-se necessário a ordenação e "[...] a complexidade de olharmos os outros não de nossos pontos de vista, expectativas, conhecimento e valores, e sim do ponto de vista de quem dança" (MARQUES, 2010, p.160).

Nessa direção, fizemos momentos de apreciação por vídeos de espetáculos, vivências dançantes da cultura popular, palestras de especialistas na área que se abordava o conteúdo (figura 2), saída da escola para assistir espetáculos (figura 3), a visitação de artistas para dançar, a professora também dançando para os estudantes e, especialmente, durante o processo criativo com os alunos, eles mesmos a apreciar uns aos outros durante as aulas. 


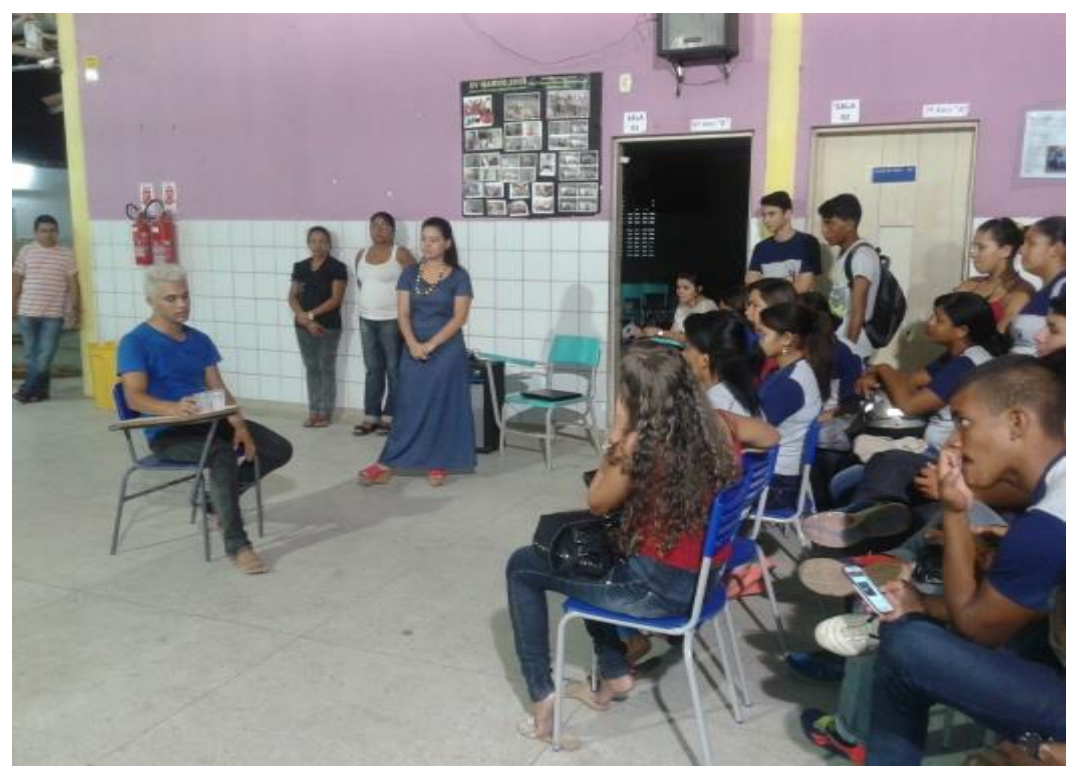

Figura 02. Bailarino Juarez Muniz em conversa pós apresentação na escola Fonte: Acervo da pesquisadora (2013)

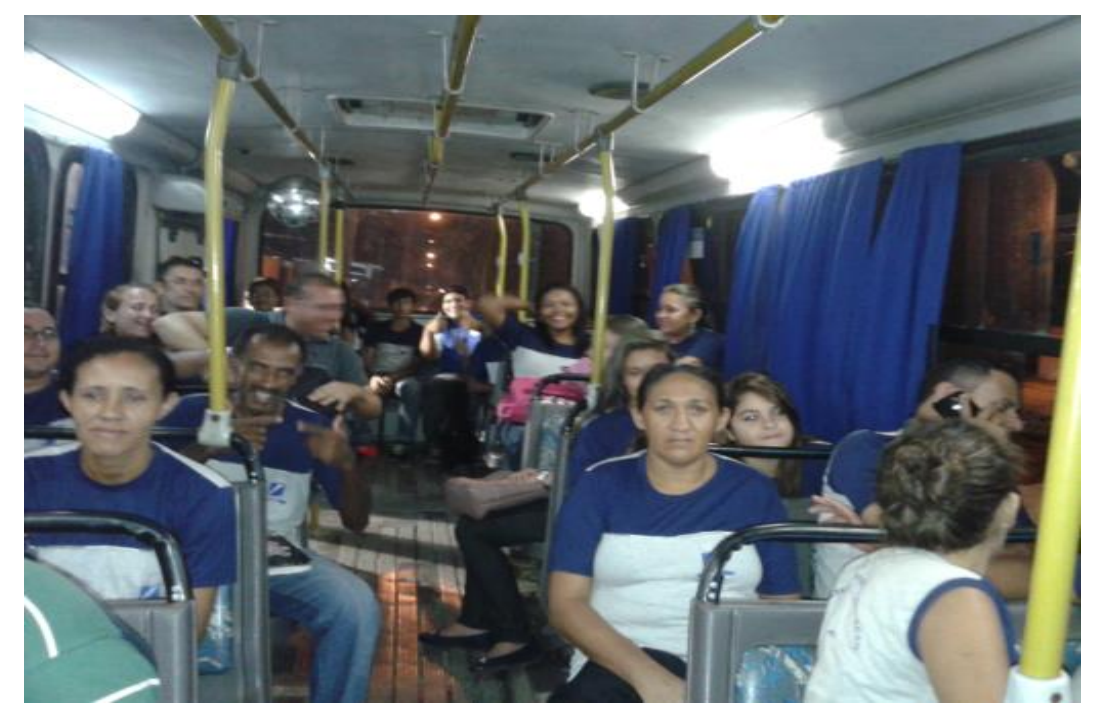

Figura 03. Ida a um espetáculo de Dança Fonte: Acervo da pesquisadora (2013)

$\mathrm{Na}$ perspectiva do fazer, abrimos espaço para vivenciar processos criativos de improvisação e composição, passando do plano da idealização à vivência no corpo que sente, realiza e percebe a si e ao outro.

Para os momentos de vivência, utilizávamos a sala de aula, reorganizando o espaço devido às carteiras existentes no local, nos fazendo perder tempo algumas vezes até na limpeza do chão para que fosse possível realizar nossas práticas. Mesmo assim, não colocamos situações como estas à frente do nosso desejo de prosseguir, mas vale pontuar nesta

Revista Digital do LAV - Santa Maria - vol. 11, n. 3, p. 122 - 137 - set./dez. 2018 ISSN 1983 - 7348 http://dx.doi.org/10.5902/1983734832833530 
escrita para que possamos nos identificar com problemas constantes que ocorrem nas escolas do país e perceber que não estamos sozinhos em determinados pontos.

Também utilizamos o pátio da escola para algumas das atividades em Dança, quando envolvia mais de uma turma na vivência (figuras 4 e 5).

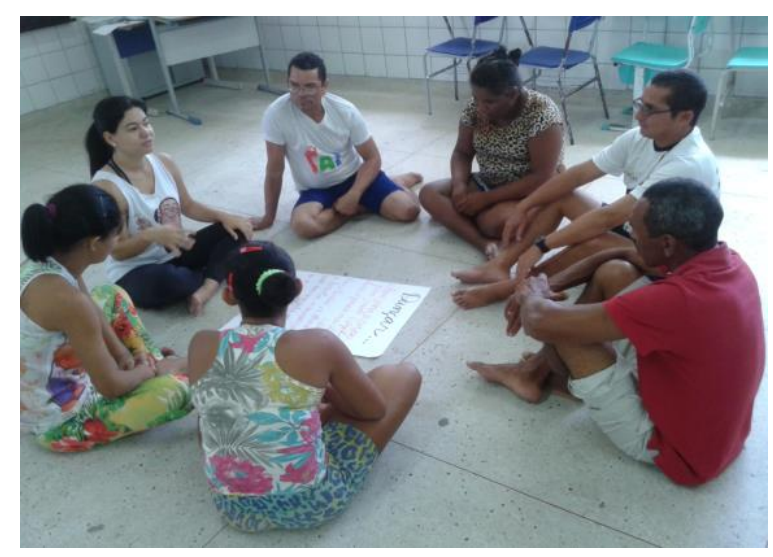

Figura 04. Aula prática

Fonte: Acervo da pesquisadora (2015)

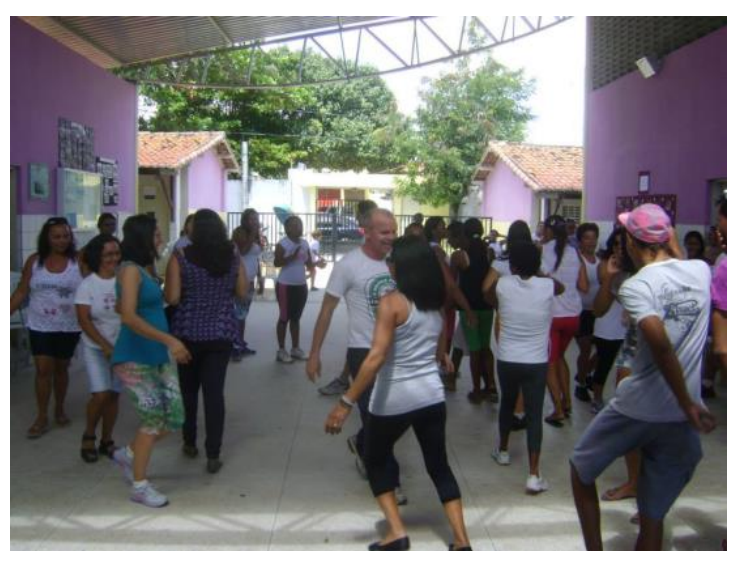

Figura 05. Aula prática no pátio

Fonte: Acervo da pesquisadora (2015)

Percebemos nesse período, junto à prática educativa dos estudantes da EJA, que a Proposta é de possível aplicação e, que a tríade, embora com objetivos específicos para cada ponta da pirâmide, se imbrica e dialoga todo tempo, pois uma dimensão bebe das demais num ciclo constante e que produz aprendizagens possíveis.

No ensino da Arte/Dança encontramos elementos favoráveis para o processo de aprendizagem de jovens e de adultos que Ihes auxiliam no desvelamento do mundo, tendo como referência primeira, seu próprio corpo, afirmando nele sua condição de existência e por ele tecendo significações que podem levar a uma melhor leitura de mundo.

\section{Considerações finais}

Para além das cortinas e dos julgamentos estéticos, a Dança surge como proposta para a Educação de Jovens e Adultos nos tempos atuais, explorando os sentidos e a percepção a fim de contribuir para as relações cotidianas do corpo social em permanente construção e ainda pouco explorado nesse contexto limitado de possibilidades que temos para este público estudantil.

Sabemos que é difícil semear em terrenos pedregosos e o que almejamos é uma terra arada e fértil para fazer prosperar aquilo que nossas expectativas docentes aguardam, mas precisamos superar o pensamento de que este terreno se encontra isolado nos alunos da

Revista Digital do LAV - Santa Maria - vol. 11, n. 3, p. 122 - 137 - set./dez. 2018 ISSN 1983 - 7348 http://dx.doi.org/10.5902/1983734832833530 
EJA, e que na verdade, ele se multiplica nas dificuldades que a educação de modo geral sempre enfrentou no país.

Os jovens-adultos merecem ser formados com aquilo que os move e, paralelamente, os forma, pois conquistando a liberdade dos seus corpos, isso poderá os conduzir a outros processos de libertação.

A Abordagem Triangular é para nós, docentes de Arte/Dança uma possibilidade para a construção desse caminho de novas oportunidades, oferecendo mais que os códigos para compreender a Dança, mas como ela pode desnudar o mundo.

\section{Referências}

ARROYO, Miguel Gonzáles. Educação de jovens-adultos: um campo de direitos e de responsabilidade pública. In: SOARES, Leôncio; GIOVANETTI, Maria Amélia; GOMES, Nilma Lino (Org.). Diálogos na educação de jovens e adultos. Belo Horizonte: Autêntica, 2005. p. 19-50.

BARBOSA, Ana Mae (Org.). Ensino da arte: memória e história. São Paulo: Perspectiva, 2008.

BRASIL. Lei 5.692, de 11 de agosto de 1971. Diretrizes e Bases para o ensino de $1^{\circ}$ e $2^{\circ}$ graus, e dá outras providências. Brasília, DF: 1971.

. MINISTÉRIO DA EDUCAÇÃO E CULTURA/CONSELHO NACIONAL DE EDUCAÇÃO.

Diretrizes Nacionais para a operacionalização do ensino de Música na Educação

Básica. Brasília, 1973.

MINISTÉRIO DA EDUCAÇÃO E CULTURA. Secretaria de Ensino de $1^{\circ}$ e $2^{\circ}$ Graus.

Educação artística: leis e pareceres. Brasília, 1982. Inclui Resolução CFE no 23/73.

Parecer no 540/1977, do CFE sobre o tratamento a ser dado aos componentes curriculares previsto no Artigo no 70 da Lei 5692/71 in documenta no 195, Rio de Janeiro, fev. 1977.

BRASIL. MEC. Lei nº. 9.394, de 20 de dezembro de 1996. Lei de Diretrizes e Bases da Educação Nacional. Brasília, DF: 20 de dezembro de 1996.

FREIRE, Paulo. Pedagogia da Tolerância. 3.ed. São Paulo: Paz e Terra, 2014.

Revista Digital do LAV - Santa Maria - vol. 11, n. 3, p. 122 - 137 - set./dez. 2018 ISSN 1983 - 7348 
FUSARI, Maria Filisminda de Rezende; FERRAZ, Maria Heloísa Corrêa de Toledo. Arte na Educação escolar. 4.ed. São Paulo: Cortez, 2010.

MACHADO, Regina. Sobre mapas e bússolas: apontamentos a respeito da Abordagem Triangular. In: BARBOSA, Ana Mae Barbosa; CUNHA, Fernanda (Org.). Abordagem Triangular no ensino das Artes e Culturas Visuais. São Paulo: Cortez Editora, 2010. p. 64-79.

MALTA. Arlene Andrade. A Aprendizagem na Educação de Jovens e Adultos: a emergência de diferentes saberes na ressignificação de práticas escolares. COLÓQUIO INTERNACIONAL PAULO FREIRE, 5, Anais... Recife, 19 a 22 setembro 2005.

MARQUES, Isabel. Ensino de Dança hoje: textos e contextos. 6.ed. São Paulo: Cortez, 2011.

Linguagem da Dança: arte e ensino. São Paulo: Digitexto, 2010.

PORPINO, Karenine. Dança é educação: interfaces entre corporeidade e estética. Natal, RN: EDUFRN, 2006.

SILVA, Maria Ozamira da Silva e. Refletindo a pesquisa participante. São Paulo: Cortez, 1986.

THIOLLENT, Michel Jean Marie. Aspectos qualitativos da metodologia de pesquisa com objetivos de descrição, avaliação e reconstrução. Cadernos de Pesquisa, n. 49, p. 4550, maio, 1984.

VIEIRA, Marcilio de Souza. História das Ideias da Dança na Educação Brasileira. Relatório de pesquisa de Estágio Pós-Doutoral, UFPB. João Pessoa, 2018.

i Possui graduação em Artes Cênicas pela Universidade Federal do Rio Grande do Norte (2007), Especialização em Ensino de Arte pela UFRN (2009) e é Mestre em Artes Cênicas pelo Programa de Pós-Graduação em Artes Cênicas da UFRN (2016). Atualmente é Professora Temporária do curso de Licenciatura em Dança ( graduação) na Universidade Federal do Rio Grande do Norte ( UFRN) e é professora da Prefeitura Municipal de Natal atuando como Coordenadora do Programa Mais Educação na Escola Municipal Noilde Ramalho. Possui experiência docente em Educação Infantil, Ensino Fundamental, Ensino Médio/Profissionalizante, Educação de Jovens e Adultos (EJA) e Ensino Superior. Cursa a graduação de Pedagogia na Universidade Federal do Rio Grande do Norte. Integra o Grupo de Pesquisa em Corpo, Dança e Processos de criação (Cirandar DEART/UFRN).

Revista Digital do LAV - Santa Maria - vol. 11, n. 3, p. 122 - 137 - set./dez. 2018 ISSN 1983 - 7348 http://dx.doi.org/10.5902/1983734832833530 
ii Pesquisador e Artista da dança, Pós Doutor pelo Instituto de Artes da Unesp, Professor Adjunto do Departamento de Artes. É Vice-Coordenador do Curso de Pós-Graduação em Artes Cênicas (PPGArC) da UFRN. Atua nos Programas de Pós-graduação em Artes Cênicas da UFRN e PROFARTES/UFRN. Possui graduação em Educação Artística com habilitação em Artes Cênicas (2002) e graduação em Educação Física (2010) pela Universidade Federal do Rio Grande do Norte. Especialista em Pedagogia do Movimento (2003) Mestre (2005) e Doutor em Educação pela UFRN (2010). Integra o Banco de avaliadores de Instituições de nível Superior - SINAES/ INEP atuando nos Cursos de Artes Cênicas e Educação Física. Membro pesquisador do Grupo de Pesquisa Corpo, Fenomenologia e Movimento (Grupo Estesia DEF/UFRN) e do Grupo de Pesquisa em Corpo, Dança e Processos de criação (Cirandar DEART/UFRN). Membro efetivo da ABRACE - Associação Brasileira de Pesquisa e Pós-Graduação em Artes Cênicas e da ANDA - Associação Nacional de Dança. Foi coordenador do Curso de Educação Física (Bacharelado e Licenciatura do UNI-RN -2010 a 2012) e do Curso de Licenciatura em Dança da UFRN (2013 a 2015).

Como citar esse artigo:

OTELO, Renata Celina de Morais ; VIEIRA, Marcilio de souza. A Abordagem Triangular como possibilidade educativa para o trabalho com Dança na Educação de Jovens e Adultos (EJA).

Revista Digital do LAV, Santa Maria: UFSM, v. 11, n. 3, p. 122-137, set./dez. 2018. 